\title{
Mobile building life cycle
}

\author{
Ivan Katranov ${ }^{1}$, and Azariy Lapidus ${ }^{1, *}$ \\ ${ }^{1}$ Moscow State University of Civil Engineering, Yaroslavskoe shosse, 26, Moscow, 129337, Russia
}

\begin{abstract}
In the publication mobile building life cycle is researched. There is comparison with the stationary construction. The article discusses in detail specialized cycles of the mobile object construction. The interrelation of specialized cycles of the mobile building object, technical, organizational and technological requirements that underlie the effective implementation of mobile building object is detected.
\end{abstract}

\section{Introduction}

There is need in buildings and constructions erected on the certain time, after all such objects are demounting and transporting on the new place or are mounting on the same place in another time in the context of sustainable development of cities. Such objects are characterizes almost complete reuse of elements of the object, that leads to cost reduction, waste and overall positive effect on environmental safety. Autonomy from energy resources and from the present the existing construction site has positive effect on the environmental situation of a specific territory (land area).

Mobile building object (MBO) - building, construction or their complex adapted to the location change or movement [1]. The sector of the mobile building is actively developing with the general growth of the world mobility [2] and with the increasing speed of the system synergy, that means there is necessity in active study its specificity for the effective implementation of the objects of such appointment.

\section{Literature review}

The life cycle of building objects is given in [3] and is represented by five main stages: predesign works, designing, building, exploitation and liquidation. Document [4] identifies the particular stages of engineering surveys (research), reconstruction and repair. In reference [5] it is discussed in detail the life cycle at the stage preceding exploitation stage for ease of use when planning the management. The life cycle of the building is described in the article [6] from the point of view of creating a infographic of the model. The problems of effectiveness of the implementation life cycle of the objects are presented in the publication [7]. Functional model of the life cycle of information spaces is considered in detail in publication [8]. The book [9] describes the features of the BIM process, depending on the stage of the object life cycle, with the introduction in the building industry information modelling. While in the

*Corresponding author: katranoff@bk.ru 
recent, forthcoming and passing the stage of discussion, the set of rules on information modeling building (BIM) [10] the object life cycle is presented similar to the source [3]. Taking into account different formulations of the building object life cycle, peculiarity of the mobile building life cycle, as well as the active implementation in the construction methods of information modelling there is a need for introduction of more general formulations of the object life cycle, allowing to build a modular structure, depending on the type of object and processes.

\section{Materials and methods}

The subject of this research is mobile building life cycle, analyzed by the method of organizational and technological Genesis [3]. To identify specialized organizational and technological cycles will compare the mobile building life cycle and stationary construction life cycle.

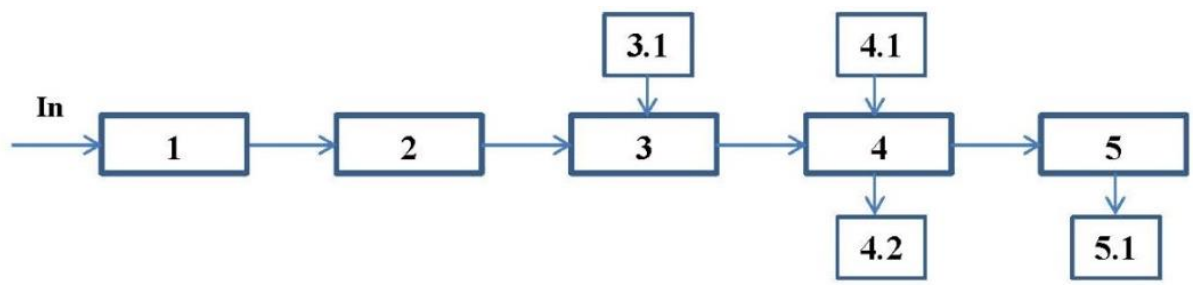

Fig. 1. Stationary construction life cycle 1- predesign; 2- designing; 3 - building; 4- operation; 5destruction [11]; 3.1.4.1- delivery; 4.2- decommission; 5.1 - utilization of wastes; In- the initiative of the object creation.

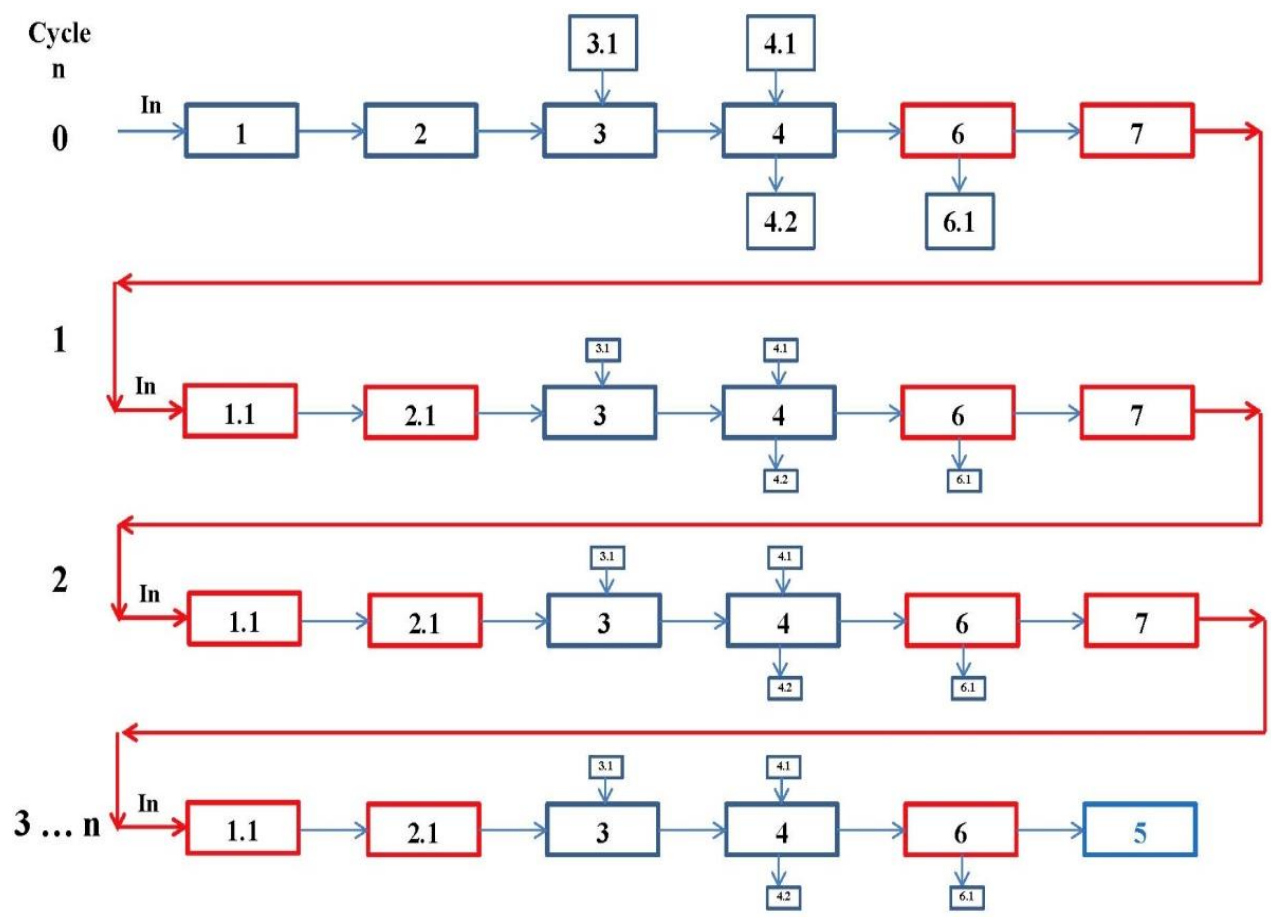

Fig. 2. The mobile building life cycle. (1- predesign; 2- designing; 3 - building; 4 - exploitation; 5 demounting; 6 - transportation; 1.1 - redesign, 3.1, 4.1- delivery; 4.2- decommission; 6.1 - utilization of wastes; In- the initiative of the object creation. 


\section{Results}

Distinctive features of the mobile building life cycle is the repetition of the cycle with partial (and in some cases) and full saving the object elements. Also there are significant differences in the stage that goes after the exploitation stage of the object life cycle, which could be characterized for stationary construction demolition of the object, recycling of waste and reclamation of the land area, while for the mobile building this stage is characterized by demounting, allowing the further use of the mobile building object (MBO). Also for the mobile building life cycle (MBLC) is it typically the stage of transportation and storage, that is not presented it the stationary construction life cycle.

On the stage of demounting of the life cycle of the object the necessity in the repeated use, the need of the analysis of the feasibility of further application of mobile building object, the fact of the need of transportation introduces a list of additional organizational and technological modules. So on the building and demounting stages of the object such modules are marking and defectoscopy, as well as packaging on the stage of the preparation for transportation of set elements of mobile building object.

The above mentioned factors confirms the need for the introduction of additional fixed requirements on the stage of preparation of technical specifications for the development of a project mobile building.

Based on the decomposition of indicators of the mobile building object [12], and the method of evaluating the effectiveness of project implementation by an integral capacity, identify the intercommunication stages and cycles general life cycle of MBO that affect the quality of the construction project fulfillment.

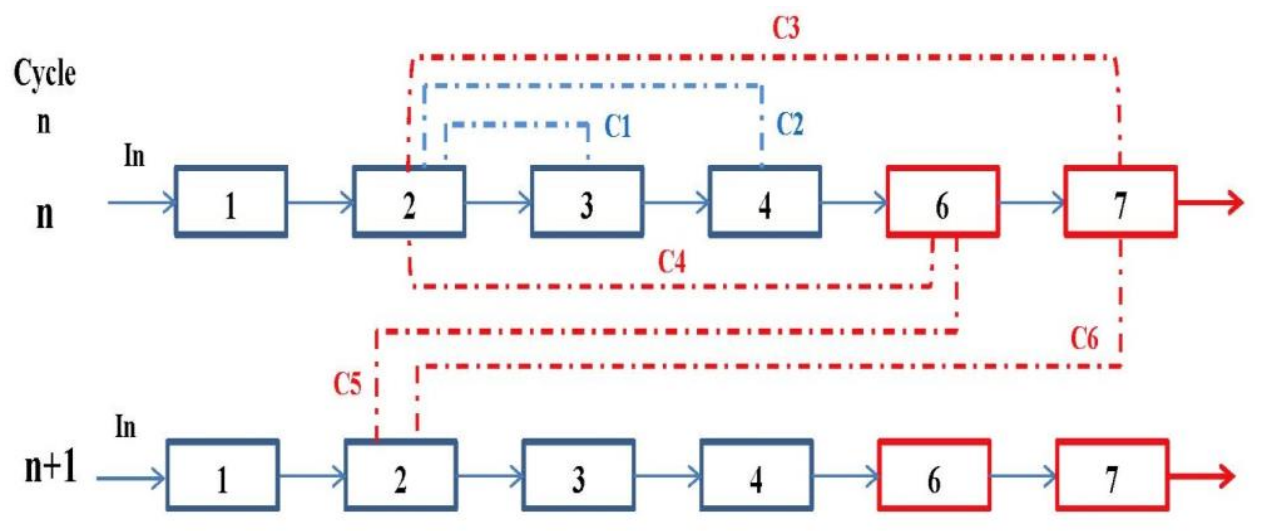

Fig. 3. The functional connection of the stages and cycles of implementation of mobile building object.

There are several specific links except the links (dependencies) typical for stationary construction object, such as $\mathrm{C} 1$ - the connection speed of building and applicable design solutions, C2- the connection of quality characteristics of exploitation from the design decisions. On the demounting, there is a connection, that influences the effectiveness of the implementation of stage 6 , precisely, the design solutions that provides minimum term and respectively the maximum speed of demounting - C3. Along with that stage 6 also has functional connections with the further building on the next cycle $(\mathrm{N}+1)-\mathrm{C} 4$. For its part transportation stage has functional relationship with the stage 2 in the form of technical solutions, providing transportation to the place of storage or new application based on the analysis of the feasibility - C5, and also the connection C6 - characterizes the functional dependence of the means of transportation, a new place and time of application of the object. 


\section{Discussion}

Revealed connections of the life-cycle stages of mobile building object allow to identify special parameters of the objects of such type for their main characteristics. So the Temporality of MBO can be characterized by predictable and unpredictable temporary need of the object. If the date and time of the construction of the projected object, as well as prospective exploitation, it is advisable the introduction of the Exact date of application and date (of service) exploitation, in accordance with the format YYYYMMDDThhmmss / PnnY $\underline{n} \underline{n} M n \underline{n} D T \underline{n} \underline{n} n_{n} M n \underline{n} S$ [6], as well as the required number of application cycles $0<$ $\mathrm{T}_{\text {экспл }} \leq 10 \mathrm{Y} \rightarrow \mathrm{nY}$ [14]. Repeatability of application and its demand is characterized by the construction cost of the project greater than the profit (economic effects) of its application for one life cycle $\mathrm{C}_{\text {object construction }}>\mathrm{Pr}_{\text {life-cycle profit, }}$ the feasibility of transporting $\mathrm{C}_{\text {displacement }}<$ $\mathrm{C}_{\text {transporting from «Plant/warehouse» }}$ depending on the distance of transportation, destination and type of transport, as well as the required rates of saving elements of MBO in one life cycle. Characteristics of repeatability of application directly related to economic parameters lifecycle and are of interest in surveying project. The minimum period of mounting and demounting of the object is characterized by a maximum speed of mounting and demounting respectively.

The autonomy of the object is characterized by autonomy from connecting to engineering networks, autonomy from the influences (including climatic), autonomy from the ground type on the construction site and autonomy from the impact of the environment.

\section{Conclusions}

The conducted study allowed us to identify the distinctive features of the life cycle of mobile building object, such as repetition cycles, specific stages of the lifecycle and their dependencies. The revealed interdependences allowed to determine specifications and special feature settings of the mobile building object, taking into account which is essential at the stage of preparation of technical specifications and in the design stage that will allow increasing the efficiency of similar projects.

\section{References}

1. I. G. Katranov, Basics of terminology of mobile construction (Construction: Science and education, 2017)

2. J. Urry, Mobilities (Polity Press, Cambridge, 2007)

3. A.A. Gusakov, System Engineering of construction (Publishing house of the ASV, Moscow, 2004)

4. An. Mottaeva, As. Mottaeva, Internet journal Science 4(23), 131 (2014)

5. S. Halliday, R. Atkins, Sustainability: RIBA Plan of Work 2013 Guide (RIBA Publishing, 2016)

6. D.Korotkov, V. Chulkov, World of sience, 1 (2013)

7. E.A. Gusakova, E.N. Kulikova, A.Z. Efimenko, V.F. Kas'yanov, Vestnik MGSU 12, 253-259 (2012)

8. A.A. Volkov, D.V. Anikin, Vestnik MGSU 11, 227-233 (2013)

9. V.V. Talapov, BIM Technology: base and genesis of building informational modeling (DMK press, Moscow, 2015)

10. An. Mottaeva, As. Mottaeva, Internet journal Science 3(22), 48 (2014) 
11. E. A. Gusakova, Y. V. Ushakova, Real Estate: Economics, management 1, 54-57 (2015)

12. A. Mottaeva, V. Lukinov, A. Mottaeva, Strategy of Management of state and municipal ownership: theory and practice (Moscow, MGSU, 2015)

13. An. Mottaeva, As. Mottaeva, Economy and Entrepreneurship 4-1(69-1), 1124-1129 (2016)

14. P.G. Graboviy, Serveying: organization, examination, management (Publishing house of the ASV, Moscow, 2015) 